\title{
Verbal and Visuospatial Short-Term and Working Memory in Children: Are They Separable?
}

\author{
Tracy Packiam Alloway and \\ Susan Elizabeth Gathercole \\ University of Durham
}

\author{
Susan J. Pickering \\ University of Bristol
}

\begin{abstract}
This study explored the structure of verbal and visuospatial short-term and working memory in children between ages 4 and 11 years. Multiple tasks measuring 4 different memory components were used to capture the cognitive processes underlying working memory. Confirmatory factor analyses indicated that the processing component of working memory tasks was supported by a common resource pool, while storage aspects depend on domain-specific verbal and visuospatial resources. This model is largely stable across this developmental period, although some evidence exists that the links between the domain-specific visuospatial construct and the domain-general processing construct were higher in the 4- to- 6-year age group. The data also suggest that all working memory components are in place by 4 years of age.
\end{abstract}

The term working memory refers to the capacity to store and manipulate information over brief periods of time (Baddeley \& Hitch, 1974; Just \& Carpenter, 1992). Extensive research over the past three decades has established that working memory is not a single store, but a memory system comprised of separable interacting components. Functioning in concert, these components provide a kind of flexible mental workspace that can be used to maintain and transform information in the course of demanding cognitive activities, and that acts as a temporary bridge between externally and internally generated mental representations. There are a range of alternative theoretical accounts of working memory capacity. Some researchers suggest that working memory consists of a domain-general aspect that coordinates information in two independent domain-specific storage components for verbal and visuospatial codes (Baddeley, 1986; see Engle, Kane, \& Tuholski, 1999a, for a review). Others argue instead that working memory resources are separated into verbal and visuospatial constructs (Shah \& Miyake, 1996). These studies have largely been restricted to adult populations. The aim of the present study was to

This research was supported by a research grant awarded by the Economic and Social Research Council of Great Britain to Tracy Packiam Alloway, Susan Elizabeth Gathercole, and Susan J. Pickering. The authors thank the schools, parents, and children who consented to participate in this study. The authors also thank Chris Jarrold and two anonymous reviewers for their helpful comments on an earlier draft of this manuscript.

Correspondence concerning this article should be addressed to Dr. Tracy Packiam Alloway, School of Education, University of Durham, Leazes Road, Durham DH1 1TA, U.K. Electronic mail may be sent to t.p.alloway@durham.ac.uk. explore, in children, whether verbal and visuospatial memory are supported by a common resource pool or whether they are maintained by separable cognitive resources. An issue of particular interest is whether the structure of working memory undergoes changes across the childhood years.

One account of domain-general working memory capacity is provided by the Baddeley and Hitch (1974) model. The central executive is the component responsible for controlling resources and monitoring information processing across informational domains (e.g., Baddeley, Emslie, Kolodny, \& Duncan, 1998; Baddeley \& Hitch, 1974). This system is also responsible for a range of regulatory functions, including the retrieval of information from long-term memory and attentional control. In this model, storage of information is mediated by two domainspecific slave systems: the phonological loop, which provides temporary storage of verbal information, and the visuospatial sketchpad, specialized for the maintenance and manipulation of visual and spatial representations (see Baddeley \& Logie, 1999, for a review). A fourth component of this model has recently been added, the episodic buffer, responsible for binding information across informational domains and memory subsystems into integrated chunks (Baddeley, 2000). This model of working memory has been supported by evidence from studies of children (e.g., Alloway, Gathercole, Willis, \& Adams, 2004), adult participants, neuropsychological patients (see Baddeley, 1996; Jonides, Lacey, \&

(C) 2006 by the Society for Research in Child Development, Inc. All rights reserved. 0009-3920/2006/7706-0014 
Nee, 2005, for reviews), and neuroimaging investigations (Vallar \& Papagno, 2003).

Domain-general accounts of working memory capacity have also been advanced by other theorists. Engle and colleagues (Engle, Tuholski, Laughlin, \& Conway, 1999b; see also Kane et al., 2004) have suggested that working memory capacity is limited by controlled attention, the ability to allocate attentional resources despite distraction or interference. Engle et al. (1999b) used a latent-variable analysis in order to extract the common variance shared by verbal short-term memory tasks such as digit span, and verbal working memory tasks such as reading span. They argued that the residual variance in verbal working memory reflected controlled processing, which was uniquely linked with general fluid intelligence. The commonality between this model and the Baddeley and Hitch (1974) working memory model (see also Baddeley, 1986) is that there is a central component that functions as a coordinator between ongoing processing of information (controlled attention and the central executive, in the respective models) and storage of information in the subsystems. Both models also incorporate domainspecific storage components: one for verbal information and another for visuospatial information. However, they can be distinguished in terms of the relationship between these storage components and of high-level cognitive abilities such as reasoning and comprehension. While in the Engle et al. (1999b) model only the controlled attentional aspect of working memory capacity is predictive of learning, in the Baddeley and Hitch (1974) model links have been established between both the central executive and the specialized storage systems and academic attainment (e.g., Pickering \& Gathercole, 2004). This theoretical distinction is addressed in a recent study by Bayliss, Jarrold, Gunn, and Baddeley (2003), who found that the ability to coordinate the processing and storage aspects of working memory tasks contributes to the prediction of reading and mathematic ability. The authors suggested that these findings provide support for a multicomponent model of working memory that includes a domain-general processing component and domain-specific storage components.

An alternative account of working memory capacity is provided by Miyake and colleagues, who have proposed that working memory capacity is supported by two separate pools of domain-specific resources for verbal and visuospatial information (Shah \& Miyake, 1996; see also Daneman \& Tardiff, 1987). Each domain is independently capable of manipulating and keeping information active.
Research on adult participants and on older children supports this distinction (Friedman \& Miyake, 2000; Jarvis \& Gathercole, 2003; Miyake, Friedman, Rettinger, Shah, \& Hegarty, 2001).

Working memory capacity is measured by complex span tasks that require simultaneous short-term storage of information while processing additional, and sometimes unrelated, information. According to domain-general accounts of working memory, the processing aspect of the task is controlled by a centralized component (i.e., the central executive or controlled attention), while the short-term storage aspect is supported by a domain-specific component (i.e., verbal or visuospatial store). From a domainspecific perspective, performance in complex tasks is a function of efficiency in either verbal or visuospatial abilities. Consequently, performance in verbal working memory tasks would not predict spatial abilities, nor would spatial working memory measures be highly associated with verbal skills. Evidence for this position has been provided by Shah and Miyake (1996; see also Friedman \& Miyake, 2000).

The principal aim of the present study was to investigate the detailed structure of working memory in childhood. A key issue addressed in the present study is whether working memory during the childhood years is best characterized by a model incorporating domain-general resources supplemented by domain-specific storage such as the working memory model of Baddeley (2000), or by a model in which working memory resources are fractionated across the verbal and visuospatial domains (e.g., Shah \& Miyake, 1996). In addition to research on adult populations (e.g., Kane et al., 2004), developmental research has supported the distinction between verbal and visuospatial short-term storage in children as young as 5 years of age. For example, Pickering, Gathercole, and Peaker (1998) found that for short-term serial recall, scores on verbal and spatial tasks were dissociable in 5- and 8year-olds, although error patterns were similar. This indicates that while different memory systems are involved in verbal and spatial short-term memory, there may be a common mechanism underlying the reconstruction of serial order that contributes to performance in both domains (see also Chuah \& Maybery, 1999).

In a broader individual differences analysis of both short-term storage tasks and working memory tasks in children, Bayliss et al.'s (2003; see also Bayliss, Jarrold, Baddeley, Gunn, \& Leigh, 2005) findings favored both a domain-general processing component and domain-specific storage components in 7- to 9-year-olds. Gathercole, Pickering, Ambridge, and 
Wearing (2004; see also Gathercole \& Pickering, 2000) extended these findings and established that there is a processing component and domain-specific storage systems in place from as young as 6 years of age. This tripartite structure of working memory was consistent across the childhood period up to 15 years. While this study confirms the relative independence of verbal and visuospatial short-term memory from an executive component associated with verbal working memory tasks, there are some limitations. In particular, there was no separate assessment of visuospatial working memory, because until recently the processing-plus-storage span tasks used to assess working memory capacities appropriate for use with children, such as listening span, counting span, and reading span, were exclusively verbal in nature (Case, Kurland, \& Goldberg, 1982; Daneman \& Carpenter, 1980).

There is considerable merit in including visuospatial working memory measures in a younger population. For example, in older children (11- and 14-year-olds), Jarvis and Gathercole (2003) found a dissociation between verbal and visuospatial working memory systems in this age group. In adult studies, Kane et al. (2004) also found that verbal and visuospatial working memory capacity was separable. It is important to determine the extent to which these findings will generalize to younger children in order to fully understand the cognitive mechanisms underpinning working memory. In the present study, the inclusion of suitable verbal and visuospatial short-term and working memory tasks, as well as a large sample of children aged between 4 and 11 years, allow us to track any developmental changes in the structure of memory.

A second aim was to investigate whether visuospatial short-term memory tasks draw more on executive resources than verbal short-term memory ones (e.g., Miyake et al., 2001; Shah \& Miyake, 1996). These data from adult samples indicate that there may be a common visuospatial construct that includes both short-term and working memory tasks. However, Kane et al. (2004) did not find any support for this position, and suggested instead that there are distinct components associated with visuospatial short-term and working memory tasks in adults (see also Bayliss et al., 2003). Again, this is an area of debate where it would be useful to identify the relationship between visuospatial memory skills and executive resources in young children before we are able to reach any clear conclusions about specific theoretical frameworks of working memory.

Participants were recruited from schools representing a broad range of performance in national assessments in English, mathematics, and science. Multiple tasks measuring four different memory components were taken in order to capture the processes underpinning working memory. The measures were taken from the Automated Working Memory Assessment (AWMA; Alloway, Gathercole, \& Pickering, 2004). The AWMA is a computerized tool for assessing short-term and working memory in children aged 4-11 years. One benefit of the AWMA is that it is designed to provide a practical and convenient way for nonexpert assessors such as teachers to screen their pupils for significant working memory problems, with a user-friendly interface. The automated presentation and scoring of tasks provide a consistency in presentation of stimuli across participants, thus reducing experimenter error.

The tasks incorporated into the computerized battery were selected on the basis of providing reliable and valid assessments of verbal and visuospatial short-term and working memory in the relevant research literature. In line with this substantial body of prior evidence, verbal and visuospatial working memory were measured using tasks involving simultaneous storage and processing of information, whereas tasks involving only the storage of information were used to measure verbal and visuospatial short-term memory. The inclusion of visuospatial working memory tasks in the present study allows us to extend findings in previous studies (e.g., Gathercole et al., 2004) to provide a comprehensive investigation of whether verbal and visuospatial memory skills develop independently across the childhood years.

The multiple assessments of each memory component taken for a large sample of children in this study provided the opportunity to use the method of confirmatory factor analysis to test alternative models of the underlying structure of working memory. Model 1 is a two-factor domain-specific model, with latent constructs for all verbal and visuospatial memory tasks. Model 2 has a two-factor structure corresponding to working memory and short-term memory, and is a fully domain-general model. The third model comprises four factors, with separate domain-specific working memory and short-term memory constructs (e.g., Friedman \& Miyake, 2000; Miyake et al., 2001). The fourth model contained three factors: a single domain-general working memory factor, and two separable storage factors for verbal and visuospatial short-term memory; this corresponds to the Baddeley and Hitch (1974) working memory model and the model advanced by Engle et al. (1999b; see also Conway, Cowan, Bunting, Therriault, \& Minkoff, 2002). Given the close 
links between working memory and academic attainment, it is important to establish whether it is domain-general executive resources or domain-specific skills represented by verbal and visuospatial working memory tasks that contribute to learning.

One important issue addressed by the study is whether the theoretical structure of working memory is consistent across childhood, or is subject to changes as a function of developmental growth. One possibility is that younger children draw more on executive resources even to perform short-term memory tasks. This could be due to the fact that the brain areas related to higher level cognition are still developing, and while older children will have acquired greater cognitive resources, younger children will not have the benefit of these additional support systems (Nelson, 1995, 2000; see also Fuster, 2000). Another possibility is that the working memory structure remains consistent across development, in line with previous findings from Gathercole et al. (2004) using a more restricted set of measures. In the present study, the fit of each theoretical model to the data was tested separately in each age group, in order to identify potential changes in short-term and working memory between 4 and 11 years.

\section{Method}

\section{Participants}

A total of 709 children from primary schools in the northeast of England participated in the study. Parental consent was obtained for each child participating in the study. Participating schools were selected on the basis of the national average of performance on Key Stage 2 assessments (national assessments in reading, writing, and mathematics) in the year 2002, and represented a range of low $(<65 \%)$, middle $(75 \%)$, and high ( $>85 \%)$ test results. The age of children ranged from 54 to 141 months (mean $=97$ months, $S D=24$ ). The majority of families served by the schools are of European heritage, with roughly $15 \%$ from immigrant families representing countries such as Pakistan, Bangladesh, China, Africa, and the Caribbean.

Information was provided by each child's principal caregiver about maternal educational level (i.e., GCSEs, A levels, vocational training, or higher education) and the age at which the mother left school. According to these socioeconomic indices, the average age at which the mother left school was 17 years (68\% of the mothers had a level of education up to this point or less), the average qualification was the final year of secondary school (54\% achieved this or less, only $7 \%$ had no academic or vocational qualifications), and the average amount of time the children in the present study attended preschool or nursery was 2 years $(77 \%$ attended for a length of time or less).

\section{Procedure}

Each child was tested individually in a quiet area of the school for a single session lasting up to $40 \mathrm{~min}$. All 12 memory measures were taken from the AWMA (Alloway et al., 2004). Six of these measures involved storage-plus-processing components and are referred to as working memory tasks. Of these, 3 measures tapped verbal ability and 3 tapped visuospatial ability. The remaining 6 measures involved storage-only components and are referred to as short-term memory tasks; 3 tasks were verbal in nature and 3 were visuospatial.

All tests were initially piloted on groups of children aged 4-5 and 9-10 years. As a result of this pilot, the tests were refined to ensure that both the practice and the experimental trials were age appropriate. Extensive practice trials that included visual illustrations of the working memory tasks were included, especially for the younger children. In particular, it should be noted that the processing and storage components of all working memory tasks were presented separated with multiple practice trials before these two elements of the task were combined in practice.

Test reliability of the AWMA was assessed in a subset of children $(n=105)$ from the standardization study randomly selected across schools. The age of children ranged from 59 to 140 months (mean $=99$ months, $S D=24$ ). A period of 4 weeks separated the two successive testing administrations. Test-retest reliabilities are reported with the description of each test. A mixed analysis of variance on recall performance at testing times 1 and 2 indicated no significant difference as a function of age.

The tests were administered in a fixed sequence designed to vary task demands as widely as possible across successive tests and to reduce fatigue. All tests were presented on a laptop computer with the screen resolution set to $600 \times 480$ pixels. The tests were designed using Borland's C ++ Builder 5 (2004). For the spoken presentation of stimuli, audio files were recorded using a minidisk player and then edited on the GoldWave program (2004). All picture files were created in Microsoft Powerpoint using the standard shape graphics.

In all of the following tests, the instructions were presented as a sound file while the computer screen 
was blank. Practice trials followed the instructions. The test trials were presented as a series of blocks; each block consists of six trials. The experimenter recorded the child's response using the right arrow key on the keyboard $(\rightarrow)$ for a correct response and the left arrow key on the keyboard $(\leftarrow)$ for an incorrect response. The computer program automatically credits a correct trial with a score of 1 . According to the "move on" rule, if a child responds correctly to the first four trials within a block of trials, the program automatically proceeds to the next block and gives credit for trials that were not administered. However, if three or more errors are made within a block of trials, the program stops the test and automatically returns to the main menu. The score for that test reflects the number of correct responses up to the point at which the test was ended. Performance on the processing component of the working memory tasks was monitored; however, errors were not included in the recall score.

\section{Tests}

Verbal short-term memory. Three measures were administered (modified from the Working Memory Test Battery for Children, WMTB-C; Pickering \& Gathercole, 2001). In the digit recall task, the child hears a sequence of digits and has to recall each sequence in the correct order. In the word recall task, the child hears a sequence of words and has to recall each sequence in the correct order. In the nonword recall task, the child hears a sequence of nonwords and has to recall each sequence in the correct order. For children aged 4.5 and 11.5 years, test-retest reliability is $.84, .76$, and .64 for digit recall, word recall, and nonword recall, respectively.

Verbal working memory. The following three measures were administered (also modified from the WMTB-C; Pickering \& Gathercole, 2001). In order to ensure that the task demands were not too difficult for the younger children (see Gathercole et al., 2004), the storage and processing components of the tasks were presented independently and then combined. Practice trials could also be repeated to ensure comprehension of the task. In the listening recall task, the child is presented with a series of spoken sentences, has to verify the sentence by stating "true" or "false," and recalls the final word for each sentence in sequence. Test trials begin with one sentence, and continue with additional sentences in each block until the child is unable to recall three correct trials at a block. In the counting recall task, the child is presented with a visual array of red circles and blue triangles. She or he is required to count the number of circles in an array and then recall the tallies of circles in the arrays that were presented. The test trial begins with one visual array, and increases by an additional visual array in each block, until the child is unable to correctly recall four trials. Each visual array stayed on the computer screen until the child indicated that she or he had completed counting all the circles. If the child made an error in counting the circles and recalled this incorrect sum, they were not penalized. In the backwards digit recall task, the child is required to recall a sequence of spoken digits in the reverse order. Test trials begin with two numbers, and increase by one number in each block, until the child is unable to recall four correct trials at a particular block. The number of correct trials was scored for each child. For children aged 4.5 and 11.5 years, test-retest reliability is .81, .79, and .64 for listening recall, counting recall, and backward digit recall, respectively.

It is worth noting that the present study included forward digit recall as a measure of verbal short-term memory and backward digit recall as a measure of verbal working memory. This decision was based on findings that in forward digit recall, the processing load is minimal as children immediately recall number sequences. In contrast, in the backward digit recall task there is an added requirement to recall the digits in reverse sequence that imposes a substantial processing load on the child as illustrated by the finding that forward digit spans are higher than backward digit spans (Isaacs \& Vargha Khadem, 1989; see also Vandierendonck, Kemps, Fastame, \& Szmalec, 2004). Correspondingly, short-term memory skills (such as forward digit recall) are much more weakly associated with general academic and cognitive performance than working memory skills as measured by backward digit recall (e.g., Daneman \& Merikle, 1996; see also Gathercole \& Alloway, 2006, for a review).

Visuospatial short-term memory. Three measures were administered. In the dot matrix task, the child is shown the position of a red dot in a series of $4 \times 4$ matrices and has to recall this position by tapping the squares on the computer screen. The position of each dot in the matrix is held on the computer for $2 \mathrm{~s}$. The sequences were random with no location being highlighted more than once within a trial. The remaining two visuospatial short-term memory measures were modified for use in the present study from the WMTB-C (Pickering \& Gathercole, 2001). In the mazes memory task, the child is shown a maze with a red path drawn through it for $3 \mathrm{~s}$. She or he then has to trace in the same path on a blank maze presented on the computer screen. In the block recall task, the child views a video of a series of blocks being tapped, and reproduces the sequence in the 
correct order by tapping on a picture of the blocks. The blocks were tapped at a rate of one block per second. For children aged 4.5 and 11.5 years, testretest reliability is $.83, .81$, and .83 for dot matrix, mazes memory, and block recall, respectively.

Visuospatial working memory. Three measures to assess visuospatial working memory that are suitable for school-aged children were developed. As with the verbal working memory tasks, the storage and processing components of the tasks were presented independently and then combined. In the first task, the odd-one-out task (adapted from Russell, Jarrold, \& Henry, 1996), the child views three shapes, each in a box presented in a row, and identifies the odd-one-out shape. At the end of each trial, the child recalls the location of each odd-one-out shape, in the correct order, by tapping the correct box on the screen. Each array is presented on the computer screen for $2 \mathrm{~s}$. Test-retest reliability is .81 for children aged 4.5 and 11.5 years.

In the $M r . X$ task (adapted from Hamilton, Coates, \& Heffernan, 2003), fictitious cartoon figures known as Mr. $\mathrm{X}$ were designed to be unfamiliar yet likable to children. The child is presented with a picture of two Mr. X figures. The child identifies whether the Mr. X with the blue hat is holding the ball in the same hand as the Mr. X with the yellow hat. The Mr. X with the blue hat may also be rotated. At the end of each trial, the child has to recall the location of each ball in Mr. $X^{\prime}$ s hand in sequence, by pointing to a picture with eight compass points. Both the Mr. X figures and the compass points stayed on the computer screen until the child provided a response. Test-retest reliability is .77 for children aged 4.5 and 11.5 years.

In the spatial span task (adapted from Jarvis \& Gathercole, 2003), the child views a picture of two arbitrary shapes, where the shape on the right has a red dot on it. The child identifies whether the shape on the right is the same as or opposite to the shape on the left. The shape with the red dot may also be rotated. At the end of each trial, the child has to recall the location of each red dot on the shape in sequence, by pointing to a picture with three compass points. Both the shapes and the compass points stayed on the computer screen until the child provided a response. Test-retest reliability is .82 for children aged 4.5 and 11.5 years.

\section{Results}

\section{Data Screening}

The data were screened for university and multivariate outliers. Univariate outliers on each of the 12 memory tasks were defined as scores more than 3.5 standard deviations above or below the mean. Ten values out of the 8,496 in the data set met this criterion and were replaced with values corresponding to \pm 3.5 standard deviations as appropriate. One multivariate outlier with a Mahanalobis $d^{2}$ score $(p<.001)$ was eliminated. The final data set for subsequent analyses consisted of 708 children.

\section{Descriptive Statistics}

The mean raw scores for each measure as a function of single year bands and gender are provided in Table 1. In all cases, improvements in performance were observed across the age bands. A series of multivariate analyses of variance (MANOVAs) were performed on each of the three measures associated with the different working memory components as a function of age in years (4-11 years) and gender. The MANOVA performed on the three verbal short-term memory tasks yielded a highly significant effect of age, $F(2,702)=52.44, p<.01$, but no significant effect of gender, $F(1,702)=1.96, p>.05$, and no significant interaction between age and gender, $F(2,702)=1.73$, $p>.05$. The same pattern of significance was observed in the MANOVAs performed on the tasks for verbal working memory-age: $F(2,702)=75.05$, $p<.01$; gender: $F(2,702)=1.26, p>.05$; interaction: $F(2,702)=2.52, \quad p>.05, \quad$ visuospatial short-term memory-age: $F(2,702)=78.52, \quad p<.01 ;$ gender: $F(2,702)=1.95, p>.05$; interaction: $F(2,702)=1.27$, $p>.05$, and visuospatial working memory-age: $F(2,702)=75.91, \quad p<.01$; gender: $F(2,702)=1.64$, $p>.05$; interaction: $F(2,702)=1.22, p>.05$. The age effects across all measures reflect the increasing memory capacity as children get older.

This pattern of performance growth as a function of age is demonstrated in Figure 1, which plots the $z$ scores for each year group from 4 to 11 years; these scores were calculated on the basis of the entire sample of children. All 12 tests indicate broadly similar developmental functions, with performance increasing across each year group. The main exception to this pattern can be observed with respect to the verbal short-term memory tasks, where performance leveled off between 10 and 11 years.

One of the principal aims of the present study was to investigate the structural organization of working memory across the range of ages of the children participating in this study. For this purpose, the children were grouped into three age bands consisting of more than 200 children each to provide satisfactory and comparable statistical stability. Means for each age band are summarized in Table 2. 


\section{Correlational Analyses}

Correlations among all variables were conducted on the full age range (rather than age bands) using the raw task scores. Zero-order correlations are displayed in the lower triangle in Table 3. The intercorrelations between measures purportedly tapping the different working memory components were substantial in magnitude, with $r$ s ranging from .56 to .73 for the verbal short-term memory tasks, .69 to .74 for the verbal working memory tasks, .68 to .75 for the visuospatial short-term memory tasks, and .64 to .73 for the visuospatial working memory tasks $(p<.001$ probability level in each case). As none of the zero-order correlations were higher than .80, multicollinearity was not a problem in this data set (Kline, 1998). It is, however, worth noting that these coefficients are inflated by the large age variation in this group. In order to adjust for this, a partial correlation analysis with age in months partialed out was calculated. These are shown in the upper triangle of Table 3. The intercorrelations between working memory measures remained moderate to high even after age is partialed out ( $r$ s ranging from .35 to .62). The within-construct coefficients were higher than between-construct coefficients, suggesting good internal validity of the measures purportedly tapping four subcomponents of working memory.

Zero-order correlations for children in the age band 4-6 years are displayed in the lower triangle of Table 4, while zero-order correlations for children in the age band 7-8 years are displayed in the upper triangle of Table 4. Zero-order correlations for children in the age band 9-11 years are displayed in Table 5. The intercorrelations between measures purportedly tapping the different memory components were robust, and in most cases there were higher within-construct correlation coefficients than between-construct coefficients. This was true for all three age bands, and reflects the pattern of relationships for the full data set as shown in Table 3.

\section{Confirmatory Factor Analyses}

The degree to which the data fitted alternative models of short-term and working memory was tested formally using confirmatory factor analysis (Bentler, 2001; Bentler \& Wu, 1995). This method provides a means of testing the adequacy of competing theoretical accounts of the relationships between measures, with each model specified in terms of paths between observed variables and latent constructs, and between constructs. A commonly 

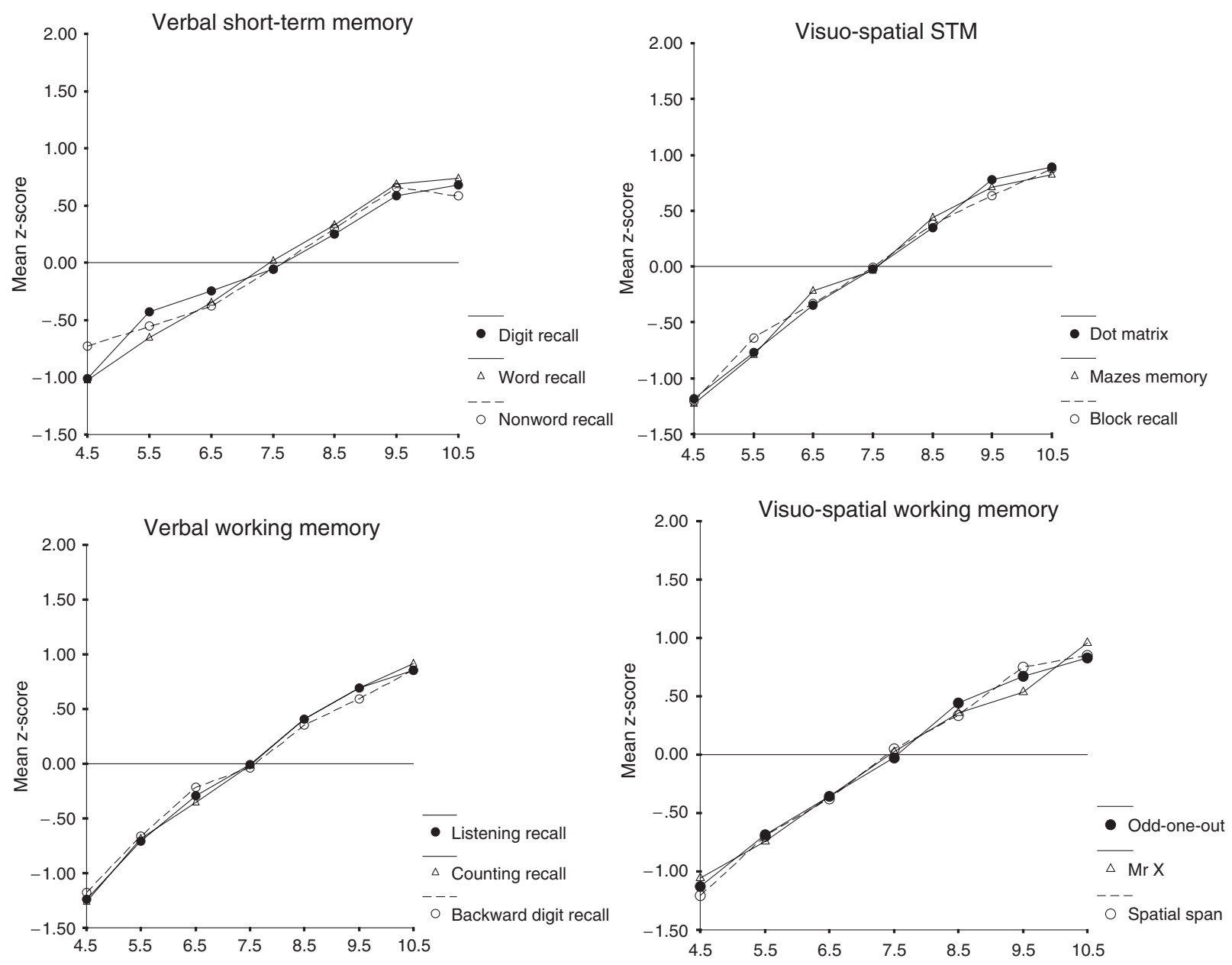

Figure 1. Mean $z$ scores as a function of age for each of the 12 measures, grouped by task type.

used index of goodness of fit for each model is the chi-square statistic, which compares the degree to which the predicted covariances in the model differ from the observed covariances. A good fit is determined by small and nonsignificant chi-square values. Because this statistic is sensitive to variances in sample sizes, with very large samples as in the present study even the best-fitting models frequently yield significant chi-square values (Kline, 1998). Model adequacy was therefore evaluated using additional global fit indices that are more sensitive to model specification than to sample size (Jaccard \& Wan, 1996; Kline, 1998). Fit indices such as the comparative fit index (CFI; Bentler, 1990), the bollen fit index (IFI; Bollen, 1989), and the normed fit index (NFI; Bentler \& Bonett, 1980) provide a further measure of fit computed by comparing the hypothesized model against a null model in which the relations between the latent variables are not specified and consequently are set at 0 . Fit indices with values equal to or higher than .90 demonstrate a good fit. Further assessment of the extent to which the specified model approximates to the true model is the root mean square error of approximation (RMSEA). An RMSEA value of .08 or lower is acceptable, and a value below .05 indicates a good fit (see McDonald \& Ho, 2002).

In the series of models tested, paths between latent constructs were left free to covary (represented diagrammatically as bidirectional links) in the absence of justifiable assumptions concerning direction of causality. Such models are known as measurement models. In each case, the level of significance of the path weights between each observed variable and its associated factor, and the correlations between all pairs of factors, was set at an $\alpha$ level of .05. Statistical comparison of models was achieved by performing chi-square difference tests (McDonald \& Ho, 2002). The statistics and fit indices generated by each of the measurement models are summarized in Table 6. In order to identify the best-fitting model, a series of chi-square difference tests were performed and are 
Table 2

Descriptive Statistics for All Test Scores as a Function of Age Band

\begin{tabular}{|c|c|c|c|c|c|c|c|c|}
\hline \multirow[b]{2}{*}{ Measure } & \multicolumn{2}{|c|}{$\begin{array}{l}4-6 \text { years } \\
(n=285)\end{array}$} & \multicolumn{2}{|c|}{$\begin{array}{c}7-8 \text { years } \\
(n=210)\end{array}$} & \multicolumn{2}{|c|}{$\begin{array}{c}9-11 \text { years } \\
(n=213)\end{array}$} & \multicolumn{2}{|c|}{$\begin{array}{l}\text { All: } 4-11 \text { years } \\
\quad(n=708)\end{array}$} \\
\hline & $M$ & $S D$ & $M$ & $S D$ & $M$ & $S D$ & $M$ & $S D$ \\
\hline \multicolumn{9}{|l|}{ Verbal short-term memory } \\
\hline Digit recall & 23.14 & 4.18 & 26.18 & 3.63 & 28.86 & 4.85 & 25.76 & 4.87 \\
\hline Word recall & 13.81 & 3.32 & 17.20 & 3.25 & 19.51 & 3.67 & 16.53 & 4.17 \\
\hline Nonword recall & 9.30 & 3.09 & 11.68 & 3.22 & 13.54 & 3.30 & 11.28 & 3.65 \\
\hline \multicolumn{9}{|l|}{ Verbal working memory } \\
\hline Listening recall & 6.46 & 3.17 & 9.98 & 2.91 & 12.31 & 3.03 & 9.27 & 3.93 \\
\hline Counting recall & 12.12 & 4.27 & 17.55 & 4.70 & 21.29 & 4.59 & 16.49 & 5.93 \\
\hline Backward digit recall & 7.14 & 3.55 & 10.73 & 3.74 & 13.41 & 3.85 & 10.09 & 4.54 \\
\hline \multicolumn{9}{|c|}{ Visuospatial short-term memory } \\
\hline Dot matrix & 14.99 & 3.64 & 19.23 & 3.47 & 22.56 & 3.70 & 18.53 & 4.81 \\
\hline Mazes memory & 9.32 & 5.69 & 15.30 & 5.23 & 19.30 & 4.69 & 14.10 & 6.74 \\
\hline Block recall & 14.37 & 3.88 & 18.56 & 3.57 & 21.42 & 3.96 & 17.74 & 4.83 \\
\hline \multicolumn{9}{|c|}{ Visuospatial working memory } \\
\hline Odd-one-out & 10.99 & 3.69 & 15.73 & 4.61 & 18.78 & 4.51 & 14.74 & 5.36 \\
\hline Mr. X & 5.95 & 3.25 & 10.05 & 4.03 & 12.81 & 3.99 & 9.23 & 4.71 \\
\hline Spatial span & 9.13 & 4.30 & 14.25 & 4.46 & 17.73 & 4.03 & 13.24 & 5.60 \\
\hline
\end{tabular}

reported following the presentation of the different model solutions.

First, models were tested on the full data set for all ages. The input to each model was the partial correlation matrix, with age partialed out. Once the best-fitting model was identified, the fit of this model was also tested for each individual age band. In these analyses also, the partial correlation matrix, controlling for age, was used as the input.

Model 1 is a two-factor model that distinguishes only between verbal and visuospatial memory con- structs. The first factor was associated with all six verbal memory measures, while Factor 2 was associated with the six visuospatial ones. The model is summarized in Figure 2, and the fit statistics are shown in Table 4. This two-factor model does not provide a good fit to the data; the chi-square value is highly significant and the fit indices are less than .90 .

In Model 2, the first factor was associated with all six working memory measures and the second factor was associated with the six short-term memory ones. The model is summarized in Figure 3, and the fit

Table 3

Correlations Between All Memory Scores; Partial Correlations (Controlling for Age in Months) in Upper Triangle

\begin{tabular}{|c|c|c|c|c|c|c|c|c|c|c|c|c|c|}
\hline Variable & 1 & 2 & 3 & 4 & 5 & 6 & 7 & 8 & 9 & 10 & 11 & 12 & 13 \\
\hline 1. Age (months) & - & & & & & & & & & & & & \\
\hline 2. Digit recall & .54 & - & .47 & .40 & .41 & .36 & .45 & .34 & .26 & .28 & .30 & .19 & .30 \\
\hline 3. Word recall & .60 & .64 & - & .62 & .31 & .35 & .34 & .28 & .32 & .25 & .30 & .17 & .23 \\
\hline 4. Nonword recall & .49 & .56 & .73 & - & .30 & .32 & .31 & .27 & .35 & .26 & .30 & .20 & .24 \\
\hline 5. Listening recall & .69 & .63 & .60 & .53 & - & .49 & .48 & .35 & .34 & .33 & .41 & .37 & .45 \\
\hline 6. Counting recall & .71 & .60 & .63 & .55 & .74 & - & .43 & .42 & .43 & .43 & .53 & .41 & .47 \\
\hline 7. Backward digit recall & .65 & .64 & .60 & .53 & .71 & .69 & - & .35 & .30 & .34 & .42 & .35 & .32 \\
\hline 8. Dot matrix & .70 & .58 & .58 & .51 & .67 & .71 & .65 & - & .42 & .54 & .37 & .31 & .36 \\
\hline 9. Mazes memory & .68 & .53 & .60 & .56 & .65 & .70 & .61 & .70 & - & .41 & .38 & .31 & .36 \\
\hline 10. Block recall & .67 & .54 & .55 & .50 & .64 & .70 & .63 & .75 & .68 & - & .39 & .33 & .40 \\
\hline 11. Odd-one-out & .66 & .55 & .58 & .52 & .68 & .75 & .67 & .67 & .66 & .66 & - & .35 & .49 \\
\hline 12. Mr. X & .66 & .48 & .50 & .46 & .66 & .69 & .63 & .63 & .62 & .63 & .64 & - & .51 \\
\hline 13. Spatial span & .69 & .56 & .55 & .49 & .71 & .73 & .62 & .67 & .66 & .68 & .73 & .73 & - \\
\hline
\end{tabular}


Table 4

Correlations Between all Memory Scores for Age Band 4-6 Years in Lower Triangle $(\mathrm{n}=285)$ and for Age Band $7-8$ Years in Upper Triangle $(\mathrm{n}=210)$

\begin{tabular}{|c|c|c|c|c|c|c|c|c|c|c|c|c|c|}
\hline Variable & 1 & 2 & 3 & 4 & 5 & 6 & 7 & 8 & 9 & 10 & 11 & 12 & 13 \\
\hline 1. Age (months) & - & .23 & .17 & .19 & .29 & .30 & .25 & .25 & .28 & .25 & .27 & .23 & .25 \\
\hline 2. Digit recall & .39 & - & .44 & .42 & .48 & .38 & .50 & .29 & .27 & .37 & .32 & .26 & .23 \\
\hline 3. Word recall & .36 & .54 & - & .60 & .39 & .33 & .37 & .26 & .28 & .28 & .29 & .24 & .17 \\
\hline 4. Nonword recall & .16 & .38 & .55 & - & .42 & .33 & .39 & .30 & .38 & .41 & .35 & .28 & .19 \\
\hline 5. Listening recall & .51 & .48 & .37 & .25 & - & .53 & .54 & .40 & .39 & .45 & .51 & .43 & .29 \\
\hline 6. Counting recall & .54 & .50 & .48 & .34 & .61 & - & .42 & .43 & .44 & .46 & .59 & .46 & .30 \\
\hline 7. Backward digit recall & .52 & .48 & .44 & .29 & .58 & .61 & - & .43 & .33 & .36 & .44 & .45 & .25 \\
\hline 8. Dot matrix & .49 & .46 & .37 & .21 & .50 & .60 & .49 & - & .46 & .45 & .42 & .32 & .25 \\
\hline 9. Mazes memory & .52 & .39 & .40 & .33 & .48 & .59 & .48 & .53 & - & .49 & .44 & .36 & .28 \\
\hline 10. Block recall & .47 & .35 & .33 & .19 & .44 & .57 & .50 & .66 & .50 & - & .47 & .42 & .48 \\
\hline 11. Odd-one-out & .51 & .46 & .45 & .34 & .54 & .65 & .57 & .48 & .51 & .47 & - & .50 & .59 \\
\hline 12. Mr. X & .45 & .30 & .23 & .22 & .52 & .55 & .40 & .49 & .47 & .48 & .47 & - & .57 \\
\hline 13. Spatial span & .45 & .40 & .30 & .22 & .54 & .57 & .41 & .44 & .44 & .45 & .53 & .57 & - \\
\hline
\end{tabular}

Note. For ages $4-6$ years, all coefficients $>.18$ are significant at the .001 level; for ages $7-8$ years, all coefficients $>.23$ are significant at the .001 level.

statistics are summarized in Table 4 . This model also did not provide a satisfactory fit of the data: the chisquare value $(p<.001)$ is highly significant, all fit indices are less than .90 , and the RMSEA value exceeds .08.

Model 3a consists of four domain-specific constructs: verbal short-term memory (Factor 1), verbal working memory (Factor 2), visuospatial short-term memory (Factor 3), and visuospatial working memory (Factor 4). This model provided a good fit of the data (see Figure 4). The chi-square value is lower than the other models (although still highly significant, $p<.001)$, all fit indices are above .90 , and the RMSEA $=.07$. It should, however, be noted that the correlation between Factors 2 (verbal working memory) and 4 (visuospatial working memory) was very high (.91), with $83 \%$ of their variance shared. In contrast, Factors 1 (verbal short-term memory) and 3 (visuospatial short-term memory) only shared $33 \%$ of their variance. This suggests that there is a greater degree of domain specificity in the short-term memory tasks than the working memory ones. In order to confirm statistically that verbal and visuospatial working memory were more strongly correlated than were verbal and visuospatial short-term memory, the path between the working memory constructs was fixed to be equal to the path between the short-term memory constructs. The fit indices for

Table 5

Correlations Between All Memory Scores for Age Band 9-11 Years

\begin{tabular}{|c|c|c|c|c|c|c|c|c|c|c|c|c|c|}
\hline Variable & 1 & 2 & 3 & 4 & 5 & 6 & 7 & 8 & 9 & 10 & 11 & 12 & 13 \\
\hline 1. Age (months) & - & & & & & & & & & & & & \\
\hline 2. Digit recall & .14 & - & & & & & & & & & & & \\
\hline 3. Word recall & .08 & .51 & - & & & & & & & & & & \\
\hline 4. Nonword recall & .03 & .48 & .73 & - & & & & & & & & & \\
\hline 5. Listening recall & .20 & .46 & .36 & .35 & - & & & & & & & & \\
\hline 6. Counting recall & .24 & .39 & .38 & .37 & .52 & - & & & & & & & \\
\hline 7. Backward digit recall & .21 & .52 & .38 & .37 & .51 & .47 & - & & & & & & \\
\hline 8. Dot matrix & .11 & .39 & .34 & .39 & .37 & .43 & .35 & - & & & & & \\
\hline 9. Mazes memory & .14 & .32 & .45 & .44 & .35 & .46 & .31 & .47 & - & & & & \\
\hline 10. Block recall & .17 & .33 & .29 & .30 & .34 & .47 & .38 & .61 & .42 & - & & & \\
\hline 11. Odd-one-out & .16 & .32 & .31 & .29 & .38 & .52 & .44 & .42 & .41 & .42 & - & & \\
\hline 12. Mr. X & .27 & .23 & .21 & .19 & .39 & .43 & .42 & .32 & .33 & .31 & .29 & - & \\
\hline 13. Spatial span & .12 & .35 & .32 & .31 & .51 & .53 & .37 & .44 & .45 & .48 & .51 & .53 & - \\
\hline
\end{tabular}

Note. All coefficients $>.20$ are significant at the .001 level. 
Table 6

Goodness-of-Fit Statistics for the Different Measurement Models for Each Age Band

\begin{tabular}{|c|c|c|c|c|c|c|c|c|}
\hline Model & $\begin{array}{l}\text { Age } \\
\text { band }\end{array}$ & $\chi^{2}$ & $d f$ & $p$ & CFI & IFI & NFI & RMSEA \\
\hline \multirow[t]{4}{*}{1} & All & 450.55 & 53 & $<.001$ & .86 & .86 & .85 & .103 \\
\hline & $4-6$ & 522.59 & 53 & $<.001$ & .82 & .82 & .80 & .112 \\
\hline & $7-8$ & 426.33 & 53 & $<.001$ & .87 & .87 & .86 & .100 \\
\hline & $9-11$ & 683.15 & 53 & $<.001$ & .82 & .82 & .81 & .130 \\
\hline \multirow[t]{4}{*}{2} & All & 441.96 & 53 & $<.001$ & .86 & .87 & .85 & .102 \\
\hline & $4-6$ & 510.45 & 53 & $<.001$ & .82 & .82 & .80 & .110 \\
\hline & $7-8$ & 452.31 & 53 & $<.001$ & .87 & .87 & .85 & .103 \\
\hline & $9-11$ & 666.66 & 53 & $<.001$ & .82 & .82 & .81 & .128 \\
\hline \multirow[t]{4}{*}{$3 a$} & All & 192.24 & 48 & $<.001$ & .95 & .95 & .94 & .065 \\
\hline & $4-6$ & 273.89 & 48 & $<.001$ & .91 & .91 & .90 & .082 \\
\hline & $7-8$ & 215.45 & 48 & $<.001$ & .94 & .94 & .93 & .070 \\
\hline & $9-11$ & 337.78 & 48 & $<.001$ & .92 & .92 & .90 & .092 \\
\hline \multirow[t]{4}{*}{$3 b$} & All & 247.09 & 49 & $<.001$ & .93 & .93 & .92 & .076 \\
\hline & $4-6$ & 351.44 & 49 & $<.001$ & .88 & .88 & .87 & .090 \\
\hline & $7-8$ & 247.99 & 49 & $<.001$ & .93 & .93 & .92 & .076 \\
\hline & $9-11$ & 383.76 & 49 & $<.001$ & .90 & .90 & .89 & .098 \\
\hline \multirow[t]{4}{*}{$3 c$} & All & 196.74 & 49 & $<.001$ & .95 & .95 & .93 & .065 \\
\hline & $4-6$ & 276.04 & 49 & $<.001$ & .91 & .91 & .89 & .080 \\
\hline & $7-8$ & 216.29 & 49 & $<.001$ & .94 & .94 & .93 & .069 \\
\hline & $9-11$ & 348.00 & 49 & $<.001$ & .91 & .91 & .90 & .093 \\
\hline \multirow[t]{4}{*}{$4 a$} & All & 226.52 & 51 & $<.001$ & .94 & .94 & .92 & .070 \\
\hline & $4-6$ & 288.03 & 51 & $<.001$ & .91 & .91 & .89 & .081 \\
\hline & $7-8$ & 292.14 & 51 & $<.001$ & .92 & .92 & .90 & .082 \\
\hline & $9-11$ & 382.22 & 51 & $<.001$ & .90 & .90 & .89 & .096 \\
\hline \multirow[t]{4}{*}{$4 b$} & All & 85.37 & 45 & $<.001$ & .98 & .98 & .96 & .062 \\
\hline & $4-6$ & 297.24 & 45 & $<.001$ & .90 & .90 & .89 & .089 \\
\hline & $7-8$ & 193.00 & 45 & $<.001$ & .95 & .95 & .94 & .068 \\
\hline & $9-11$ & 326.25 & 45 & $<.001$ & .92 & .92 & .91 & .094 \\
\hline
\end{tabular}

this Model 3b, are included in Table 4 . A chi-square difference test comparing the fit of this model ( $3 \mathrm{~b}$ ) with Model 3a resulted in a significant decrease in the model fit $\left(\Delta \chi^{2}=54.85, d f=1, p<.001\right)$. This indicates that working memory capacity is a more domain-general construct than short-term memory.

The next issue we investigated was whether visuospatial memory tasks require greater involvement of the central executive component than do verbal memory tasks. In Model 3a, the correlation between visuospatial short-term and working memory was only slightly higher than that between verbal shortterm and working memory (.78 compared with .68). In Model 3c, the path between visuospatial shortterm and working memory constructs was fixed to be equal to the path between the verbal short-term and working memory constructs, and the fit values were good. The fit indices for this Model 3c, are also included in Table 4. A chi-square difference test comparing Model 3c with Model 3a indicated that the model fit was not significantly reduced $\left(\Delta \chi^{2}=4.50, d f=1, p>.01\right)$. This suggests that visuospatial short-term memory tasks do not tap executive resources any more than verbal short-term memory ones.

While Model 3a seems to provide an adequate fit to the data, there are concerns of multicollinearity due to the high correlation between Factors 2 (verbal working memory) and 4 (visuospatial working memory). In order to address this problem, we tested a three-factor model consisting of the following: a domain-general construct incorporating both the verbal and visuospatial storage-plus-processing tasks, a verbal short-term memory construct, and a visuospatial short-term memory construct (see Figure 5). This model is consistent with the tripartite working memory model of Baddeley and Hitch (1974), as well as that of Engle et al. (1999b). The

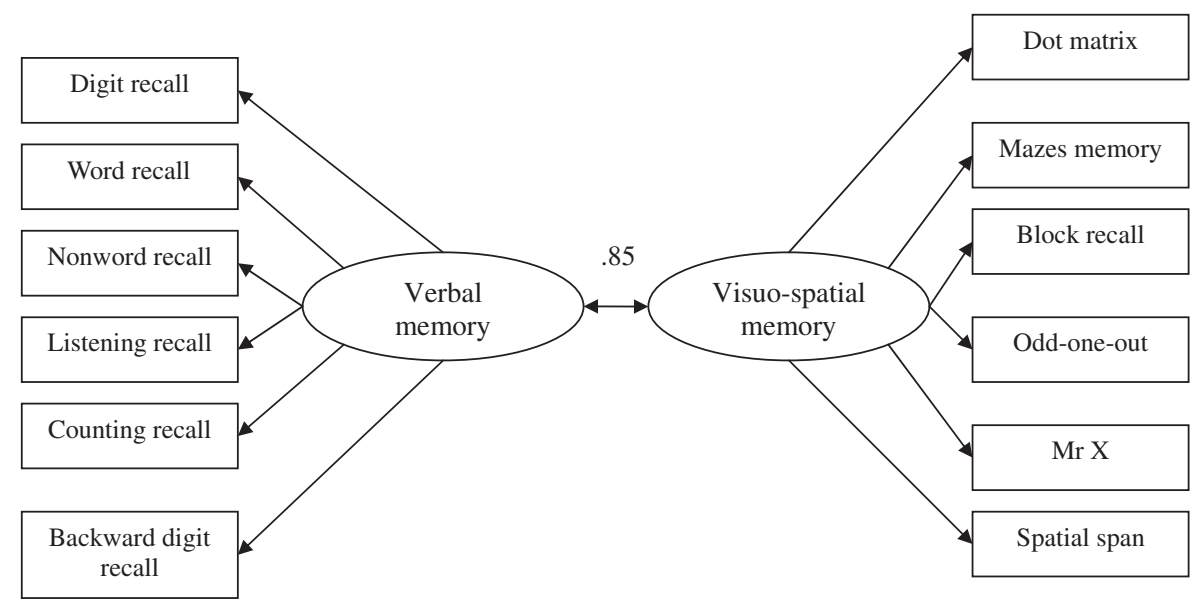

Figure 2. Path model for the two-factor model based on the distinction between verbal and visuospatial memory skills (Model 1). For clarity, only path coefficients between latent variables for the full data set are shown. 


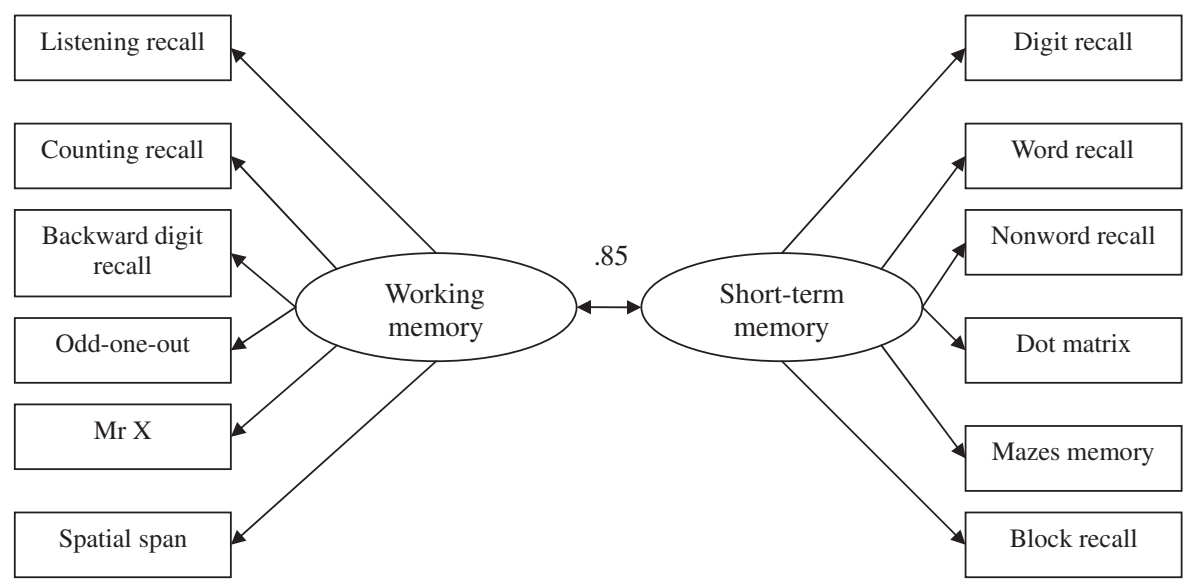

Figure 3. Path model for the two-factor model based on a domain-specific view of short-term and working memory (Model 2). For clarity, only path coefficients between latent variables for the full data set are shown.

model is summarized in Figure 5, and the model statistics are shown in Table 4. This model (4a) provided a better fit to the data than either Models 1 or 2, with a lower chi-square value (although still highly significant, $p<.001$ ). All fit indices were .94 or above, and the RMSEA $=.05$, indicating a satisfactory fit.

In order to apply a current theoretical model of working memory based on adult data to the present data from children (e.g., Conway et al., 2002), a final model ( $4 \mathrm{~b})$ was tested. In this, the variance shared by the processing aspect of verbal and visuospatial working memory tasks was represented by a common factor, while the storage element involved in these tasks loaded on both this factor as well as domain-specific constructs for the verbal and visuospatial short-term memory tasks. This model contrasts with Model 4a, where shared variance between both the processing and storage aspects of the verbal and visuospatial working memory tasks was represented by one factor. The chi-square value was considerably lower and all fit indices were above .90 , and the RMSEA $=.06$. In addition to providing a good account of the data, the correlations between latent constructs were also satisfactory. The fit indices for this model are included in Table 4 (Model 4b). A chi-square difference test comparing the fit of this model with Models 3a $\left(\Delta \chi^{2}=141.15, d f=3, p<.001\right)$ and $4 \mathrm{a}\left(\Delta \chi^{2}=106.87\right.$, $d f=6, p<.001)$ confirmed that this model provides the best account of these data. This indicates that while verbal and visuospatial working memory tasks share the involvement of executive functioning (Baddeley, 2000) or controlled attention (Engle et al., $1999 \mathrm{~b}$ ), the storage requirements of these tasks are separable. The model solution for the full data set is

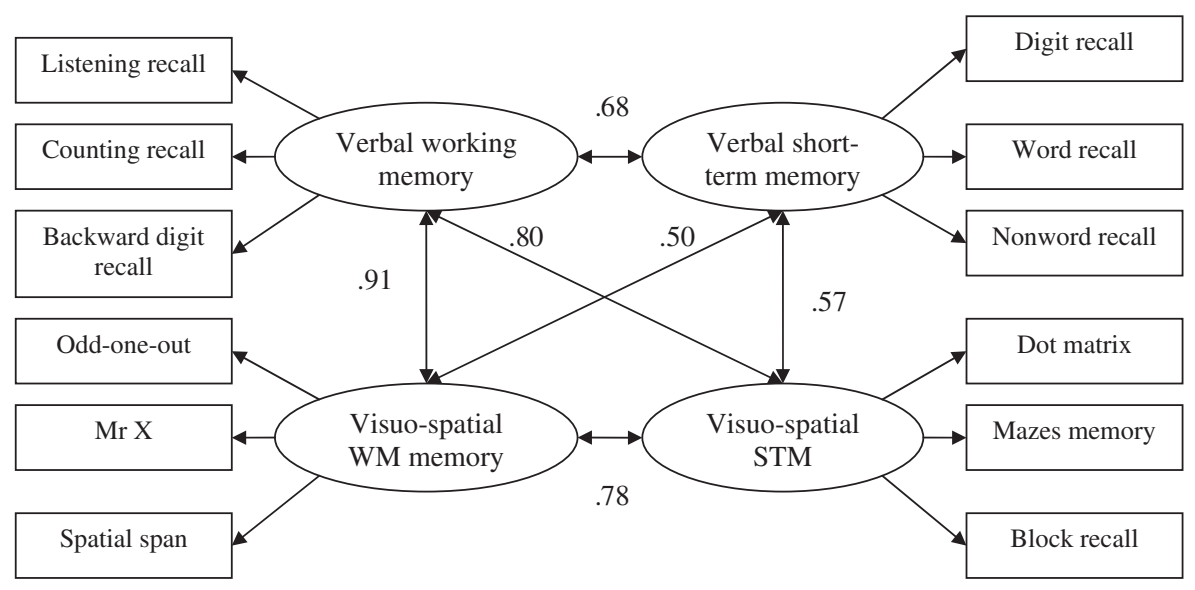

Figure 4. Path model based on distinct verbal and visuospatial working memory components and domain-specific storage components (Model 3a). For clarity, only path coefficients between latent variables for the full data set are shown. 

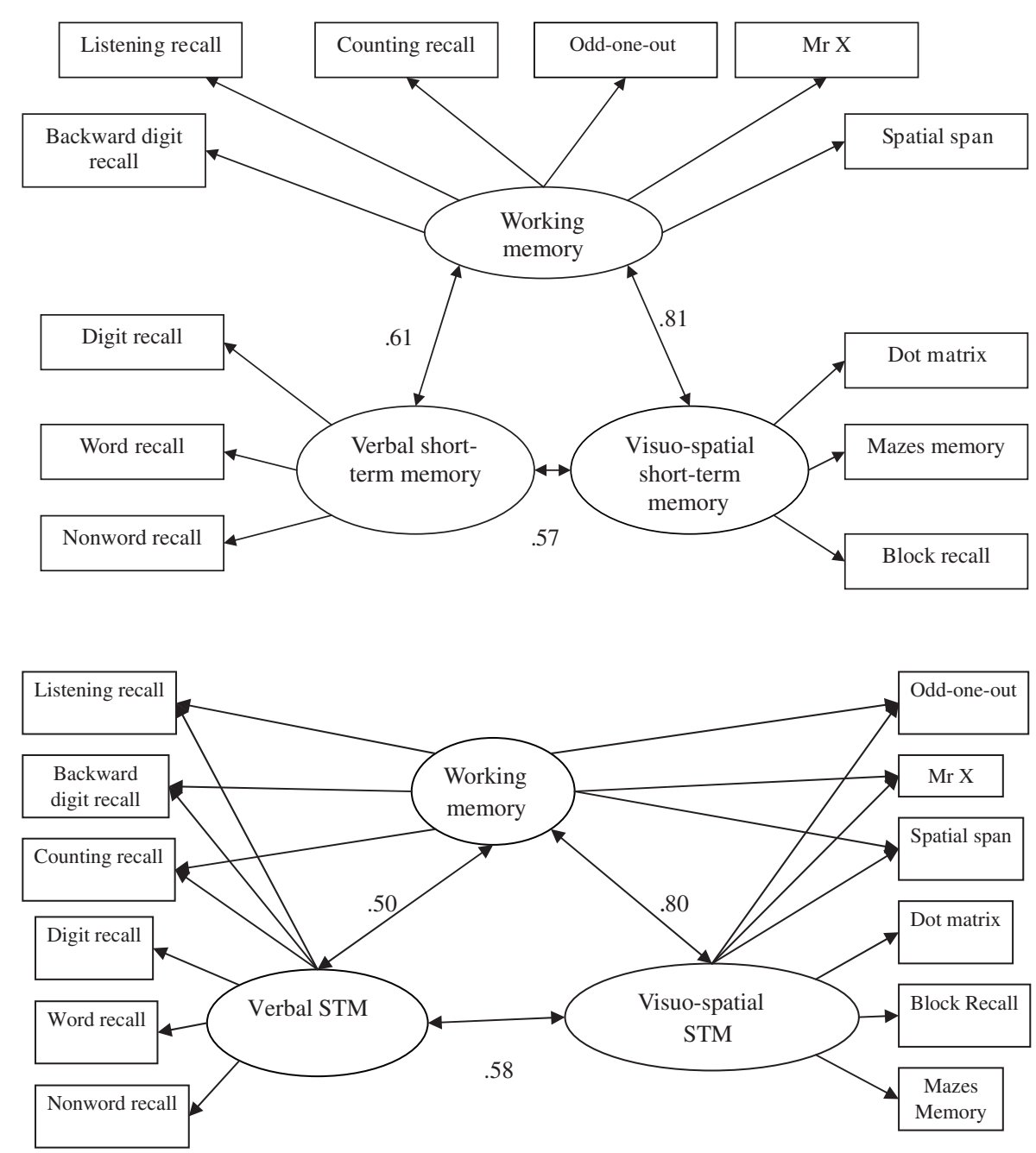

All ages

Figure 5. Path model for the three-factor model based on the tripartite model of working memory, with a distinction between verbal shortterm and working memory, and a separate factor for visuospatial memory (Model 4a). For clarity, only path coefficients between latent variables for the full data set are shown.

summarized in Figure 6. For reasons of parsimony and theoretical coherence (given the multicollinearity problem of Model 3a), this model is accepted as providing a suitable fit to the data.

A series of confirmatory factor analyses was conducted to test the fit of each of these different measurement models across the age range represented in the present study. The partial correlation matrix was used as the input for three different age bands: $4-6,7-8$, and 9-11 years. The fit indices for each of these models are provided in Table 4. Of specific interest is whether the components of Model $4 \mathrm{~b}$ are equivalent across the three age bands. The findings are similar to that of the model for the full data set. Models 1 and 2 did not provide a good fit with the data, and multicollinearity was a problem for Models 3a and 3c. Across the three age bands, Model $4 \mathrm{~b}$ provided a very good fit with the data. Two chi-square difference test comparing the fit of this model with Models 3a and 4a confirm that this three-factor order model provides the best account of these data. The model comparison statistics are described in Table 7. The path coefficients between each of the latent constructs in Model $4 \mathrm{~b}$ across each of three age bands are summarized in Figure 6.

It is worth noting that in Model $4 b$, the path between the working memory construct and visuospatial short-term memory was very high for the 4- to 6-year-olds (.97). It is possible that these children were reliant solely on executive resources to perform the visuospatial tasks. In order to test this, we fixed the correlations between working memory and visuospatial 


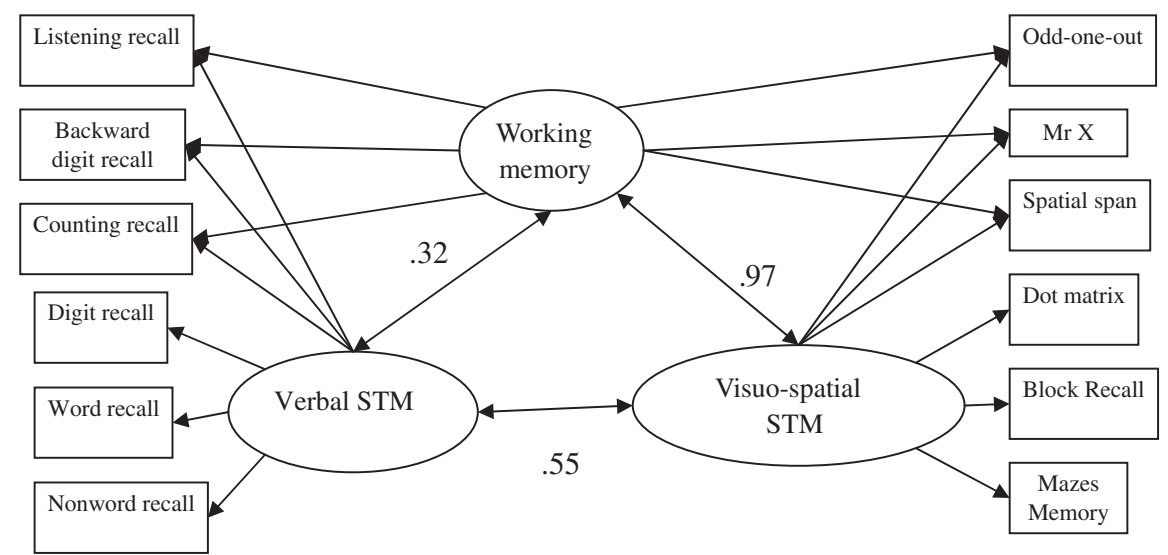

4 to 6 years

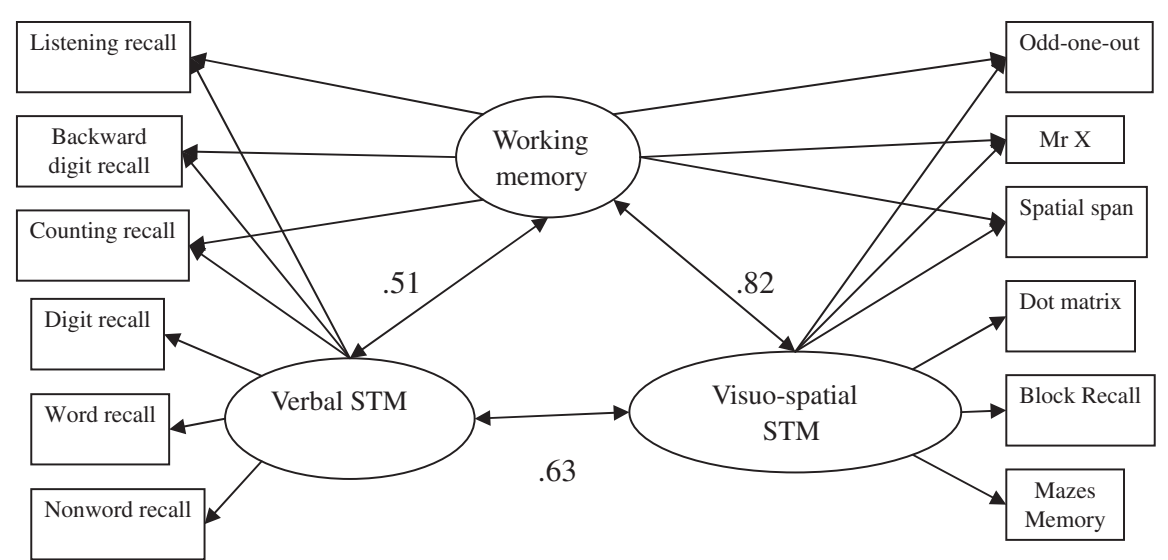

7 to 8 years

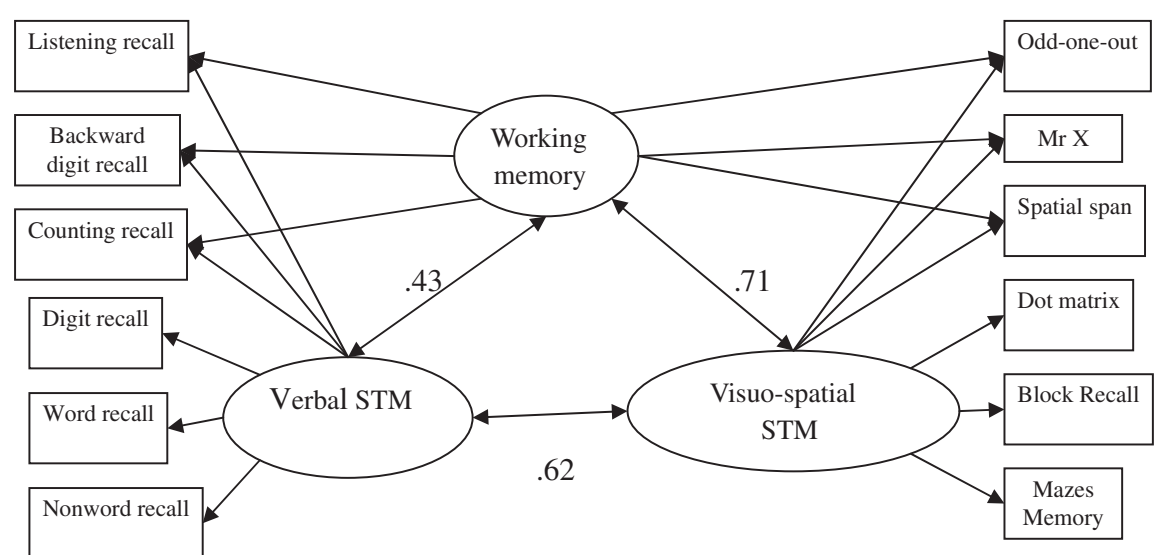

9 to 11 years

Figure 6. Four path models for each age band (4-6,7-8,9-11 years, and the full data set) for the three-factor model based on a common processing factor for verbal and visuospatial working memory tasks and domain-specific factors for verbal and visuospatial storage (Model $4 \mathrm{~b}$ ). All factor loadings are significant at the $p<.05$ level.

short-term memory at 1.0 to indicate a perfect correlation. The data indicate no significant decrease in the fit of the model when the correlation was set to 1.0 for the 4- to 6-year-olds. However, for the older children (7-8, 9-11 years, and the full data set), there was a significant decrease in the model fit. This finding is important as it indicates that for the visuospatial short-term memory tasks, the younger 
Table 7

Model Comparison Statistics for Each Age Band Between Models $4 b$ and $3 a$, and $4 b$ and $4 a$

\begin{tabular}{|c|c|c|c|c|c|c|}
\hline \multirow[b]{2}{*}{ Age band } & \multicolumn{3}{|c|}{ Model 3a } & \multicolumn{3}{|c|}{ Model 4a } \\
\hline & $\Delta \chi^{2}$ & $d f$ & $p$ & $\Delta \chi^{2}$ & $d f$ & $p$ \\
\hline All & 141.15 & 3 & $<.001$ & 106.87 & 6 & $<.001$ \\
\hline $4-6$ years & -23.35 & 3 & $<.001$ & -9.21 & 6 & ns \\
\hline $7-8$ years & 22.45 & 3 & $<.001$ & 99.14 & 6 & $<.001$ \\
\hline $9-11$ years & 11.53 & 3 & $<.01$ & 55.97 & 6 & $<.001$ \\
\hline
\end{tabular}

Note. $n s=$ not significant. $\Delta \chi^{2}=\chi^{2}$ difference.

children base their performance on resources associated with the central executive (or controlled attention) to a larger extent than older children do.

\section{Discussion}

The purpose of the present study was to investigate whether the structure of working memory is consistent across the childhood years. The first issue addressed in the study was whether working memory capacity in childhood could be viewed as a domain-general construct that coordinates separate codes for verbal and visuospatial storage or whether it is a domain-specific construct with distinct resources for verbal and visuospatial information. The second issue was whether visuospatial short-term memory tasks draw more on executive resources than verbal short-term memory ones. A key feature of the present study is that it is one of the few studies to examine these theoretical issues of the structure and interrelationships of working memory components in childhood using multiple assessments, including tasks for visuospatial working memory, in a large sample with a wide age range. It extends previous developmental research such as that of Gathercole et al. (2004; see also Bayliss et al. 2003, 2005) where the theoretical structure of working memory from 6 years old was examined. In the present study, the inclusion of children as young as 4 years and visuospatial working memory measures such as the odd-one-out, Mr. X, and spatial span provides a better understanding of the theoretical structure of memory in childhood and how it develops in this crucial period.

The developmental functions from 4 to 11 years for each aspect of memory tapped by the AWMA (verbal short-term and working memory and visuospatial short-term and working memory) were comparable, showing steady improvements in accuracy across age groups. One exception was that performance in verbal short-term memory tasks leveled off sooner than in other tasks. No sex differences were found in any of the tasks. The correlation analyses indicate stronger relationships between measures purported to tap the same underlying memory component than with measures of other memory components. As careful consideration was given to design of the memory tasks, the theoretical structure appears to reflect underlying differences in the cognitive processes associated with these different measures rather than task-specific similarities and differences. While there were differences in surface features across the tasks, an important underlying aspect was that all tasks provided a measure of the capacity of memory, rather than a reflection of knowledge or information acquired by the child. For example, in the verbal short-term memory tasks, both word and number tasks were used in order to avoid performance reflecting knowledge-based skills in only literacy or numeracy. Also, consistent with research on working memory, the verbal and visuospatial short-term memory tasks involved only storage of information, while the verbal and visuospatial working memory measures involved simultaneous processing and storage of information. For example, in the listening recall task, the child judged the veracity of the sentence and then recalled the final word; in the spatial span task, the child determined whether one shape was a mirror image of the other and then recalled the location of a red dot. The findings from the present study support the idea that any differential patterns of performance reflect the underlying cognitive mechanisms responsible for performance rather than the nature of the tasks.

In order to address the issue of domain generality versus specificity of working memory capacity, several key theoretical models were compared using confirmatory factor analysis. A three-factor model, with related but separable constructs representing measures of verbal and visuospatial storage and a third factor representing the shared variance between the verbal and visuospatial working memory tasks (Model $4 \mathrm{~b}$ ), provided the best account of the interrelationships between measures of short-term and working memory across the different age bands. Thus, the interrelationships between measures of working memory and short-term memory appeared to be stable across this developmental period, and also suggested that this underlying cognitive structure for memory is in place as young as 4 years. Although there are domain-specific aspects related to short-term memory capacity associated with verbal and visuospatial codes, working memory 
capacity is primarily driven by a domain-general mechanism. This is in line with the view that the processing aspect of the tasks shares the involvement of executive functioning (Baddeley, 2000) or controlled attention (Engle et al., 1999a). It is worth noting that there is some evidence of development change; in particular, links between the domaingeneral processing construct and the domain-specific visuospatial construct were higher in the 4-6 age band compared with the other two age groups, a point that we will return to later.

An alternative model consistent with the view of domain-specific constructs for verbal and visuospatial memory measures (e.g., Friedman \& Miyake, 2000; Miyake et al., 2001) was also tested (Model 3a). However, in this model the correlation between verbal and visuospatial working memory was very high and they shared a large amount of variance $(83 \%)$. This suggests that verbal and visuospatial working memory capture more common underlying cognitive skills than verbal and visuospatial shortterm memory tasks. In adult studies reporting distinguishable verbal and spatial working memory constructs, Kane et al. (2004) point out that these constructs also share $70-90 \%$ of their variance (e.g., Kyllonen, 1993; Oberauer, Süß, Schulze, Wilhelm, \& Wittmann, 2000). It is then perhaps unsurprising that a similar pattern was observed in our developmental population. This proposal fits in with the view of the central executive, which is responsible for controlling resources and monitoring information processing (Baddeley, 2000). It is also compatible with the view that controlled attention works to keep taskrelevant information active in working memory (e.g., Engle et al., 1999a).

A strength of the present study was the heterogeneity of the population sampled, which was drawn from a full range of demographic backgrounds and academic attainment. One explanation for the finding of domain specificity in adult samples could be the result of a homogeneous population, a point made by Shah and Miyake (1996) to explain the domain specificity in their data. Kane et al. (2004) also suggested that when participants are pooled from selective universities, the range of cognitive abilities is restricted, and it is therefore more useful to recruit from a broad participant pool in order to gain a more general understanding about working memory skills.

The second research question addressed the issue of whether visuospatial short-term memory tasks draw more on executive resources than verbal ones. Looking at the verbal domain first, the findings are consistent with previous research in developmental populations (e.g., Gathercole et al., 2004) and in adult samples (e.g., Kane et al., 2004; Park et al., 2002) that verbal short-term memory tasks consist of a storageonly component, whereas working memory measures require executive resources for the processing aspect of the task. This pattern is consistent across all three age groups, indicating no developmental change in the relationship between verbal short-term and working memory.

With respect to the visuospatial domain, the results indicate differences in the developmental patterns. Specifically, the data reveal that the link between the domain-specific visuospatial construct and the domain-general processing construct was higher in the $4-6$ age band compared with the other two age groups. Indeed, when the correlation between these two variables was fixed to represent a perfect association, there was no significant decrease in the fit of this model for the youngest age group. However, this was not the case for the older age groups, confirming that young children draw more on executive resources (or controlled attention) than older children when performing the visuospatial short-term memory tasks (e.g., Cowan et al., 2005).

One explanation for this finding can be drawn from the idea of developmental fractionation (Hitch, 1990), that is cognitive mechanisms can develop at different rates. Using tasks of visuospatial short-term memory, Pickering, Gathercole, Hall, and Lloyd (2001) found evidence of a developmental fractionation, which they proposed was the result of whether the tasks had a static or dynamic presentation format. There is growing evidence to suggest that executive functions support the more dynamic aspects of visuospatial tasks, including tracking visual sequences and transforming visuospatial images (e.g., Duff \& Logie, 1999; Logie, 1995). In the present study, the visuospatial short-term memory tasks included dynamic formats, such as the perceptuo-motor tracking of dots and block in the dot matrix and block recall tasks, respectively. Thus, the high association between visuospatial short-term memory tasks and working memory for younger children in the present study fits in well with the idea that dynamic formats of visuospatial tasks involve executive functions as well. This is an important finding as very few developmental studies have explored this relationship between visuospatial short-term and working memory across a range of ages, including children as young as 4 years old (however, for research on older children, see Bayliss et al., 2003; Jarvis \& Gathercole, 2003; Pickering et al., 1998).

A related issue regarding the theoretical structure of visuospatial memory concerns the extent to which 
it is visual or spatial. Neuropsychological evidence provides evidence for an impaired spatial but preserved visual memory (Hanley, Young, \& Pearson, 1991), and vice versa (Farah, Hammond, Levine, \& Calvanio, 1988). Data on selective interference of memory for spatial information with concurrent spatial movements (Baddeley \& Lieberman, 1980), and of visual memory with interference by visual items (Quinn \& McConnell, 1996) also support this position. Other studies have found differential levels of performance on a block sequence and visual pattern memory tasks, which has been interpreted as supporting a fractionation of visual and spatial working memory (e.g., Logie \& Pearson, 1997; Pickering et al., 2001). It is important to note, however, that in the present study there is no support for findings of dissociable visual and spatial aspects of the visuospatial short-term memory tasks. Performance on the dot matrix task, which is similar to the visual patterns test, and the block recall task is not markedly different (see Tables 1 and 2). Moreover, the age-related improvements are consistent for both visual and spatial short-term memory tasks (see Figure 1). Indeed, Gathercole et al. (2004) found similar developmental trajectories for these tasks as well (see also Alloway, 2006). There are two possible explanations for why other studies have found a dissociation between visual and spatial short-term memory. First, Gathercole (1998) suggested that in practice it is difficult to utilize a task that taps purely visual or spatial components of memory. Second, an alternative explanation for findings of dissociable visual and spatial memory performance could be due to the static versus dynamic presentation formats of the tasks rather than a visual/spatial distinction (Pickering et al., 2001). Similarly, in the present study, the dynamic presentation of all the visuospatial tasks may have resulted in the undifferentiated performance for the traditionally visual (dot matrix) and spatial (block recall) tasks.

A further interesting point concerns the relationship between verbal and visuospatial short-term memory. The strength of association between these two variables increases slightly from the 4- to 6-age group to the older age bands ( $7-11$ years). This is in line with the view that younger children rely more on visual codes initially, but as they get older they use strategies such as rehearsal to recode visual material using verbal labels (e.g., Hitch, Halliday, Schaafstal, \& Schraagen, 1988). This is not inconsistent with the view that these two types of storage tasks are domain specific as the data from the present study indicate that a common short-term memory construct (Model 2) was not a suitable fit to the data. However, it does provide some initial support for development of strategies as a function of age.

The findings have valuable implications for learning. There is now extensive evidence of a causal link between impairments of verbal working memory and learning difficulties (Alloway, Gathercole, Adams, \& Willis, 2005; Gathercole \& Alloway, 2004; Swanson \& Siegel, 2001). In a recent observational study, we found that children with such impairments often fail in classroom learning activities that place heavy demands on working memory (Gathercole, Lamont, \& Alloway, 2006). On this basis, we have suggested that excessive working memory load disrupts the incremental process of acquiring skill and knowledge, and so underlies the learning difficulties associated with working memory impairments (Gathercole, 2004). In atypical populations, there is a specificity of memory impairments. For example, a recent study has found that children with specific language impairment perform poorly on all verbal memory measures but within the normal range on visuospatial memory ones, while children with developmental coordination disorder perform below age-expected levels in both verbal and visuospatial memory measures (Alloway \& Archibald, 2005). The development of a standardized tool such as the AWMA provides an important opportunity for the theoretical exploration of the specificity of links between verbal and visuospatial memory and scholastic attainment in an atypically developing population.

In conclusion, the findings from the present study indicate that the theoretical structure of working memory capacity is consistent with the view that there are domain-specific components for storage, and a domain-general component for processing information. This structural organization of memory can be reliably assessed from as young as 4 years and remains constant across the childhood years.

\section{References}

Alloway, T. P. (2006). Working memory and children with developmental coordination disorders. In T. P. Alloway \& S. E. Gathercole (Eds.), Working memory and neurodevelopmental conditions (pp. 161-187). New York: Psychology Press.

Alloway, T. P., \& Archibald, L. M. (2006). Working memory and learning in children with developmental coordination disorder and specific language impairment. Manuscript submitted for publication.

Alloway, T. P., Gathercole, S. E., Adams, A. M., \& Willis, C. (2005). Working memory and other cognitive skills as predictors of progress towards early learning goals at school entry. British Journal of Developmental Psychology, $23,417-426$. 
Alloway, T. P., Gathercole, S. E., \& Pickering, S. J. (2004). The automated working memory assessment. Test battery available from authors.

Alloway, T. P., Gathercole, S. E., Willis, C., \& Adams, A. M. (2004). A structural analysis of working memory and related cognitive skills in early childhood. Journal of Experimental Child Psychology, 87, 85-106.

Baddeley, A. D. (1986). Working memory. New York: Oxford University Press.

Baddeley, A. D. (1996). Exploring the central executive. Quarterly Journal of Experimental Psychology, 49A, $5-28$.

Baddeley, A. D. (2000). The episodic buffer: A new component of working memory? Trends in Cognitive Sciences, 4, 417-422.

Baddeley, A. D., Emslie, H., Kolodny, J., \& Duncan, J. (1998). Random generation and the executive control of working memory. Quarterly Journal of Experimental Psychology, 51A, 819-852.

Baddeley, A. D., \& Hitch, G. (1974). Working memory. In G. Bower (Ed.), The psychology of learning and motivation (Vol. 8, pp. 47-90). New York: Academic Press.

Baddeley, A. D., \& Lieberman, K. (1980). Spatial working memory. In R. S. Nickerson (Ed.), Attention and performance VIII (pp. 521-539). Hillsdale, NJ: Lawrence Erlbaum Associates Inc.

Baddeley, A. D., \& Logie, R. H. (1999). The multiple-component model. In A. Miyake \& P. Shah (Eds.), Models of working memory: Mechanisms of active maintenance and executive control (pp. 28-61). New York: Cambridge University Press.

Bayliss, D. M., Jarrold, C., Baddeley, A. D., Gunn, D. M., \& Leigh, E. (2005). Mapping the developmental constraints on working memory span performance. Developmental Psychology, 41, 579-597.

Bayliss, D. M., Jarrold, C., Gunn, D. M., \& Baddeley, A. D. (2003). The complexities of complex span: Explaining individual differences in working memory in children and adults. Journal of Experimental Psychology: General, 132, $71-92$.

Bentler, P. M. (1990). Comparative fit indexes in structural models. Psychological Bulletin, 107, 238-246.

Bentler, P. M. (2001). EQS Structural Equation Modelling Software (Version 6.0) [Computer software]. USA: mvsoft.

Bentler, P. M., \& Bonett, D. G. (1980). Significance tests and goodness of fit in the analysis of covariance structures. Psychological Bulletin, 88, 588-606.

Bentler, P. M., \& Wu, E. J. C. (1995). EQS for Macintosh User's Guide. Encino, CA: Multivariate Software Inc.

Bollen, K. A. (1989). Structural equations with latent variables. New York: John Wiley \& Sons Inc.

Borland's C + + Builder 5. (2004). Borland International.

Case, R., Kurland, D. M., \& Goldberg, J. (1982). Working memory capacity as long-term activation: An individual differences approach. Journal of Experimental Psychology: Learning, Memory and Cognition, 19, 1101-1114.

Chuah, Y. M. L., \& Maybery, M. T. (1999). Verbal and spatial short-term memory: Common sources of devel- opmental change? Journal of Experimental Child Psychology, 73, 7-44.

Conway, A. R. A., Cowan, N., Bunting, M. F., Therriault, D. J., \& Minkoff, S. R. B. (2002). A latent variable analysis of working memory capacity, short-term memory capacity, processing speed, and general fluid intelligence. Intelligence, 30, 163-183.

Cowan, N., Elliott, E. M., Saults, J. S., Morey, C. C., Mattox, S., Hismjatullina, A., et al. (2005). On the capacity of attention: Its estimation and its role in working memory and cognitive aptitudes. Cognitive Psychology, 51, 42-100.

Daneman, M., \& Carpenter, P. A. (1980). Individual differences in working memory and reading. Journal of Verbal learning and Verbal Behaviour, 19, 450-466.

Daneman, M., \& Merikle, P. M. (1996). Working memory and language comprehension: A meta-analysis. Psychonomic Bulletin and Review, 3, 422-433.

Daneman, M., \& Tardiff, T. (1987). Working memory and reading skill reexamined. In M. Coltheart (Ed.), Attention and performance XII: The psychology of reading (pp. $491-$ 508). Hillsdale, NJ: Erlbaum.

Duff, S. C., \& Logie, R. H. (1999). Storage and processing in visuo-spatial working memory. Scandinavian Journal of Psychology, 40, 251-259.

Engle, R. W., Kane, M. J., \& Tuholski, S. W. (1999a). Individual differences in working memory capacity and what they tell us about controlled attention, general fluid intelligence, and functions of the prefrontal cortex. In A. Miyake \& P. Shah (Eds.), Models of working memory: Mechanisms of active maintenance and executive control (pp. 102-134). New York: Cambridge University Press.

Engle, R. W., Tuholski, S. W., Laughlin, J. E., \& Conway, A. R. A. (1999b). Working memory, short-term memory, and general fluid intelligence: A latent variable approach. Journal of Experimental Psychology: General, 125, 309-331.

Farah, M. J., Hammond, K. M., Levine, D. N., \& Calvanio, R. (1988). Visual and spatial mental imagery: Dissocia ble systems of representation. Cognitive Psychology, 20, $439-462$.

Friedman, N. P., \& Miyake, A. (2000). Differential roles for visuospatial and verbal working memory in situation model construction. Journal of Experimental Psychology: General, 129, 61-83.

Fuster, J. M. (2000). Executive frontal functions. Experimental Brain Research, 133, 66-70.

Gathercole, S. E. (1998). The development of memory. Journal of Child Psychology and Psychiatry, 39, 3-27.

Gathercole, S. E. (2004). Working memory and learning during the school years. Proceedings of the British Academy, 125, 365-380.

Gathercole, S.E, \& Alloway, T. P. (2004). Working memory and classroom learning. Dyslexia Review, 15, 4-9.

Gathercole, S.E, \& Alloway, T. P. (2006). Working memory deficits in neurodevelopmental disorders. Journal of Child Psychology and Psychiatry, 47, 4-15.

Gathercole, S. E., Lamont, E., \& Alloway, T. P. (2006). Working memory in the classroom. In S. Pickering (Ed.), Working memory and education (pp. 219-240). Elsevier Press. 
Gathercole, S. E., \& Pickering, S. J. (2000). Assessment of working memory in six- and seven-year-old children. Journal of Educational Psychology, 92, 377-390.

Gathercole, S. E., Pickering, S. J., Ambridge, B., \& Wearing, H. (2004). The structure of working memory from 4 to 15 years of age. Developmental Psychology, 40, 177-190.

GoldWave Inc. (2004). GoldWave Digital Audio Editor Software, Version 5. St. Johns: GoldWave Inc.

Hamilton, C. J., Coates, R. O., \& Heffernan, T. (2003). What develops in visuo-spatial working memory development? European Journal of Cognitive Psychology, 15, 43-69.

Hanley, J. R., Young, A. W., \& Pearson, N. A. (1991). Impairment of the visuo-spatial sketchpad. Quarterly Journal of Experimental Psychology, 43A, 101-125.

Hitch, G. J. (1990). Developmental fractionation of working memory. In G. Vallar \& T. Shallice (Eds.), Neuropsychological impairment of short-term memory (pp. 221-246). Cambridge, UK: Cambridge University Press.

Hitch, G. J., Halliday, S., Schaafstal, A. M., \& Schraagen, J. M. C. (1988). Visual working memory in young children. Memory and Cognition, 16, 120-132.

Isaacs, E. B., \& Vargha Khadem, F. (1989). Differential course of development of spatial and verbal memory span: A normative study. British Journal of Developmental Psychology, 7, 377-380.

Jaccard, J., \& Wan, C. K. (1996). LISREL approaches to interaction effects in multiple regression. Thousand Oaks, CA: Sage Publications.

Jarvis, H. L., \& Gathercole, S. E. (2003). Verbal and nonverbal working memory and achievements on national curriculum tests at 11 and 14 years of age. Educational and Child Psychology, 20, 123-140.

Jonides, J., Lacey, S. C., \& Nee, D. E. (2005). Processes of working memory in mind and brain. Current Directions in Psychological Science, 14, 2-5.

Just, M. A., \& Carpenter, P. A. (1992). A capacity theory of comprehension: Individual differences in working memory. Psychological Review, 99, 122-149.

Kane, M. J., Hambrick, D. Z., Tuholski, S. W., Wilhelm, O., Payne, T. W., \& Engle, R. W. (2004). The generality of working-memory capacity: A latent-variable approach to verbal and visuo-spatial memory span and reasoning. Journal of Experimental Psychology: General, 133, 189-217.

Kline, R. B. (1998). Principles and practice of structural equation modelling. New York: Guilford.

Kyllonen, P. C. (1993). Aptitude testing inspired by information processing: A test of the four-sources model. Journal of General Psychology, 120, 375-405.

Logie, R. H. (1995). Visuo-spatial working memory. Hove, UK: Erlbaum.

Logie, R. H., \& Pearson, D. G. (1997). The inner eye and the inner scribe of visuo-spatial working memory: Evidence from developmental fractionation. European Journal of Cognitive Psychology, 9, 241-257.

McDonald, R. P., \& Ho, R. M. (2002). Principles and practice in reporting structural equation analyses. Psychological Methods, 7, 64-82.
Miyake, A., Friedman, N., Rettinger, D. A., Shah, P., \& Hegarty, M. (2001). How are visuospatial working memory, executive functioning, and spatial abilities related? A latent-variable analysis. Journal of Experimental Psychology: General, 130, 621-640.

Nelson, C. A. (1995). The ontogeny of human memory: A cognitive neuroscience perspective. Developmental Psychology, 31, 723-738.

Nelson, C. A. (2000). Neural plasticity and human development: The role of early experience in sculpting memory systems. Developmental Science, 3, 115-136.

Oberauer, K., Süß, H.-M., Schulze, R., Wilhelm, O., \& Wittmann, W. W. (2000). Working memory capacityfacets of a cognitive ability construct. Personality and Individual Differences, 29, 1017-1045.

Park, D. C., Lautenschlager, G., Hedden, T., Davidson, N., Smith, A. D., \& Smith, P. K. (2002). Models of visuospatial and verbal memory across the adult life span. Psychology and Aging, 17, 299-320.

Pickering, S. J., \& Gathercole, S. E. (2001). Working memory test battery for children. London: Psychological Corporation Europe.

Pickering, S. J., \& Gathercole, S. E. (2004). Distinctive working memory profiles in children with special educational needs. Educational Psychology, 24, 393-408.

Pickering, S. J., Gathercole, S. E., Hall, M., \& Lloyd, S. A. (2001). Development of memory for pattern and path: Further evidence for the fractionation of visuo-spatial memory. Quarterly Journal of Experimental Psychology, 54A, 397-420.

Pickering, S. J., Gathercole, S. E., \& Peaker, S. M. (1998). Verbal and visuo-spatial short-term memory in children: Evidence for common and distinct mechanisms. Memory and Cognition, 26, 1117-1130.

Quinn, J. G., \& McConnell, J. (1996). Irrelevant pictures in visual working memory. Quarterly Journal of Experimental Psychology, 49A, 200-215.

Russell, J., Jarrold, C., \& Henry, L. (1996). Working memory in children with autism and with moderate learning difficulties. Journal of Child Psychology and Psychiatry, 37, 673-686.

Shah, P., \& Miyake, A. (1996). The separability of working memory resources for spatial thinking and language processing: An individual differences approach. Journal of Experimental Psychology: General, 125, 4-27.

Swanson, H. L., \& Siegel, L. (2001). Learning disabilities as a working memory deficit. Issues in Education. Contributions from Educational Psychology, 7, 1-48.

Vallar, G., \& Papagno, C. (2003). Neuropsychological impairments of short-term memory. In A. D. Baddeley, M. D. Kopelman, \& B. A. Wilson (Eds.), Handbook of memory disorders (pp. 249-270). Chichester, UK: John Wiley \& Sons.

Vandierendonck, A., Kemps, E., Fastame, M. C., \& Szmalec, A. (2004). Working memory components involved in the Corsi block test. British Journal of Psychology, 95, 57-79. 